\title{
FORAMINÍFEROS BENTÓNICOS COMO INDICADORES PALEOECOLÓGICOS DE LA FORMACIÓN USCARI (MIOCENO TEMPRANO-MEDIO), CUENCA DE LIMÓN (SUR), COSTA RICA
}

\author{
BENTHIC FORAMINIFERA AS PALEOECOLOGICAL INDICATORS OF THE \\ USCARI FORMATION (EARLY TO MIDDLE MIOCENE), LIMÓN BASIN \\ (SOUTH), COSTA RICA
}

\author{
Julliet Betancur \\ Escuela Centroamericana de Geología, Universidad de Costa Rica \\ Apdo. 214-2060 UCR, Costa Rica \\ julliet.velez@gmail.com
}

(Recibido: 12/12/2013 ; aceptado: 30/03/2014)

\begin{abstract}
The Uscari Formation (Torito and Calvario rivers, 3X, Peralta and Alto Guayacán), shows a shallowing from lower bathyal zones to neritic zones during the Early Miocene. In the Middle Miocene there was a change back to bathyal zones, but not as deep as those found in the $3 \mathrm{X}$ area during the previous interval.

During the Early Miocene bathyal zones were characterized by eutrophic to mesotrophic environments deposited under oceanic upwelling and turbidity flows conditions, except for the $3 \mathrm{X}$ area that had a more stable fauna. The shallowing towards neritic zones is characterized by oligotrophic environments with hard substrates and high-energy sands, with the presence of reefs, algae and warm waters. During the Middle Miocene, bathyal zones were oligotrophic and diversity was low possibly due to increased predation or a change in the circulation of intermediate waters by the influence of Northern Component Water (NCW), a precursor of the current North Atlantic Deep Water (NADW), which is characterized by oxygenated waters, is carbonate-rich and is low in nutrients.

The bathyal zone of the study area correlates with the bottom of the Terciopelo creek section and Early Miocene Period of the Reventazón river. Both the bathyal and abyssal deposits of the Reventazón river section, and the mid bathyal zone of the Terciopelo creek section were subject to turbidites flows which brought shallow taxa into deep water. During the late Early Miocene and early Middle Miocene, the middle and upper Terciopelo creek section was deposited in the upper slope to shelf environments transition. The early Middle Miocene type section of the Uscari creek was deposited on the continental shelf and is tentatively correlated to the top of the Terciopelo creek section.

Keywords: Limón Basin, Uscari Formation, benthic foraminifera, microhabitat, epifaunal, infaunal, oligotrophic, mesotrophic, eutrophic.
\end{abstract}




\begin{abstract}
RESUMEN: La Formación Uscari (en los ríos Torito y Calvario, y las secciones 3X, Peralta y Alto Guayacán), muestra una somerización desde zonas batiales inferiores hasta zonas neríticas durante el Mioceno Temprano. En el Mioceno Medio cambia nuevamente a zonas batiales no tan profundas como las alcanzadas en el área de 3X, durante el intervalo anterior.

Durante el Mioceno Temprano las zonas batiales estuvieron caracterizadas por ambientes eutróficos a mesotróficos depositadas bajo condiciones de surgencia oceánica y flujos de turbidez, a excepción de $3 \mathrm{X}$ que muestra una fauna más estable. La somerización hacia zonas neríticas se caracterizó por ambientes oligotróficos, con sustratos duros y arenosos de alta energía, con presencia de arrecifes, algas y aguas cálidas. Durante el Mioceno Medio, las zonas batiales eran oligotróficas y presentaban la menor diversidad de todas las muestras, debido posiblemente a una mayor predación o a un cambio en la circulación de las aguas intermedias por la influencia del Componente de Agua Norte (North Component Water, $\mathrm{NCW}$ ), precursor de la actual Agua Profunda del Atlántico Norte (North Atlantic Deep Water, NADW), caracterizada por aguas oxigenadas, ricas en carbonatos y pobre en nutrientes.

La zona batial del área de estudio se correlaciona con la parte inferior de la quebrada Terciopelo y el Mioceno Temprano del río Reventazón. Tanto los depósitos batiales y abisales de la sección río Reventazón, y el batial medio de la sección quebrada Terciopelo estuvieron sujetas a turbiditas y a la introducción de taxones someros en agua profunda. Durante el Mioceno Temprano Tardío y el Mioceno Medio Temprano, la parte media y superior de la sección quebrada Terciopelo, resultó en la transición de pendiente superior a ambientes de plataforma. La sección tipo del Mioceno Medio temprano de la quebrada Uscari fue depositada en la plataforma continental y se correlaciona tentativamente con la parte superior de la quebrada Terciopelo.

Palabras clave: Cuenca de Limón, Formación Uscari, foraminíferos bentónicos, microhabitat, epifaunal, infaunal, oligotrófico, mesotrófico, eutrófico.
\end{abstract}

\section{INTRODUCCION}

Las paleoreconstrucciones paleoceanográficas basadas en asociaciones de foraminíferos bentónicos, sugieren que éstas pueden relacionarse con diferentes masas de agua, especialmente las de agua profunda ya que han mostrado una estabilidad importante en la evolución de su morfología desde hace 14 millones de años (Mioceno Medio; Kennett, 1982). Debido a esta evolución ecológica conservativa, se puede extrapolar con la ecología moderna y así, reconstruir la historia de la circulación oceánica profunda (Kennett, 1982). Para las interpretaciones paleoecológicas basadas en foraminíferos modernos se asume, entonces que las adaptaciones fisiológicas de las especies no cambian con el tiempo, ni cambia su distribución con la profundidad (Douglas, 1979).

El alimento y el requerimiento de oxígeno en aguas de fondo y aguas intersticiales, también controlan los microambientes preferenciales de las especies, lo cual se refleja en la abundancia, distribución y morfología de las conchillas (e.g.
Ingle et al., 1980; McCorkle \& Emerson, 1988; Gooday, 1994; Loubere, 1996). Condiciones disaeróbicas, i.e. concentraciones de oxígeno < $2 \mathrm{ml} / \mathrm{L}$, se encuentran frecuentemente a profundidades batiales entre 100 y $1500 \mathrm{~m}$, en zonas de surgencia y en cuencas pobremente ventiladas (Gooday, 1994). Algunos taxones como Bulimina abundan en ambientes disaeróbicos mientras que otros como Uvigerina abundan en zonas de alta productividad, independiente de su grado de oxigenación (Gooday, 1994).

\section{CONTEXTO GEOLÓGICO}

La Formación Uscari constituye parte del relleno sedimentario depositado en la Cuenca Limón Sur, Costa Rica. Esta fue denominada informalmente por Berry en 1921 (en Collins \& Coates, 1999). Posteriormente se formaliza el nombre y se define como sección tipo la quebrada Uscari, tributaria del río Amoura que desemboca en el río Sixaola (Olson, 1922, (en: Collins \& 
Coates, 1999). Debido a que la sección tipo no tiene una ubicación precisa y a que posiblemente no este expuesta actualmente, Cassel \& Sen Gupta (1989) designan una nueva sección de referencia a lo largo de la quebrada Terciopelo $(62 \mathrm{~km}$ al oeste de la ciudad de Limón).

La Formación Uscari es diacrónica y es considerada de edad Mioceno Medio a Tardío. El intervalo del Mioceno Medio se encuentra en la quebrada Uscari. El Mioceno Tardío se encuentra en la desembocadura del río Watsi, en las cercanías del contacto con la Formación Río Banano (Pizarro, 1985).

Browne (1961) describe a la Formación Uscari como compuesta de arcillolitas y limolitas con un rango de edad Oligoceno Tardío (Miembro Brai) y Mioceno Temprano-Medio (Miembro Yorkin). Las profundidades durante el Oligoceno Tardío variaban desde aguas muy profundas hasta someras hacia el tope de la sucesión. Cassell (1986) determina, para la parte basal en la quebrada Terciopelo, una edad Oligoceno Tardío, depositada en aguas someras; durante el Mioceno Temprano cambia hacia aguas profundas, y se someriza hacia el Mioceno Medio Temprano. La sección entre el Mioceno Tardío y el Plioceno Temprano la considera como Formación Río Banano. Campos (2001) divide la Formación Uscari en tres miembros o intervalos, la inferior de edad Mioceno Temprano, la media de edad Mioceno Medio y la superior de edad Mioceno Tardío, constituida esencialmente de arcilla depositada desde pendientes batiales a prodeltas. El espesor de la Formación Uscari es de 2000 m aproximadamente, de sedimentos siliclásticos de agua somera del Mioceno Tardío, interpretado como un depósito de plataforma influenciado por un delta (Brandes et al., 2007).

Los foraminíferos de la Formación Uscari han sido descritos por Goudkokk \& Porter (1942; en: Collins \& Coates, 1999), Browne (1961), Pizarro (1985), Cassell (1986), Cassel y Sen Gupta (1989), y Collins \& Coates (1999). Las áreas estudiadas corresponden a las quebradas Uscari y Terciopelo, y a los ríos Watsi,
Reventazón, Sandbox, y las localidades Carbón Dos y Guayacán. Para los ríos Torito y Calvario, solo se reportan estudios relacionados con amenazas naturales y geológicas (Pérez, 1996; Sibaja, 1996; Chavarría, 1996; Barahona et al., 2012).

La evolución geológica de la Cuenca Limón Sur se interpreta como una cuenca de arco trasero en el Campaniano Tardío sobre el basamento regional del Complejo ofiolítico de Nicoya. El relleno de esta cuenca ocurrió en dos episodios principales: sedimentación de aguas profundas entre el Campaniano Tardío y el Mioceno Temprano y sedimentación marina somera a continental desde el Mioceno Medio hasta el Reciente (Campos, 2001).

La estratigrafía de la base al techo, corresponde a la Formación Changuinola, con $1280 \mathrm{~m}$ de carbonatos pelágicos intercalados con sedimentos volcaniclásticos de agua profunda (Campaniano Tardío a Maastrichtiano). Formación Tuis, con 3000 m turbiditas volcaniclásticas gruesas, depósitos de flujo de escombros, flujos de lava, de edad Paleoceno a Eoceno Temprano (Brandes et al., 2007).

Durante el Eoceno al Oligoceno, fuerzas tectónicas compresionales (convergencia entre Norte y Sur América) causaron una inversión del margen de cuenca y la formación de altos estructurales. Sobre el tope de estas áreas levantadas, se establecieron sistemas de carbonatos como la Formación Las Animas de 150-200 m de espesor. Contemporáneamente, $700-900 \mathrm{~m}$ de lodos hemipelágicos, turbiditas calcáreas, depósitos carbonatados de flujos de escombros (Formación Senosri), se depositaron en las cuencas adyacentes (Brandes et al., 2007).

Durante el Oligoceno Tardío, se desarrolla una inconformidad, causada probablemente por un levantamiento regional del arco de isla y a una caída del nivel del mar, subsecuentemente, se formaron rampas carbonatadas en el tope de esta inconformidad. Estas rampas están sobreyacidas por aproximadamente $2000 \mathrm{~m}$ de sedimentos silicoclásticos del Mioceno Tardío (Formación Uscari). Durante el Mioceno Tardío al Plioceno, se depositó la Formación Río Banano, localmente asociada con arrecifes de parche (Brandes et al., 2007). 


\section{METODOLOGÍA}

Se recolectaron 20 muestras de sedimento, de $300 \mathrm{~g}$ en promedio, en lugares que se consideraron in situ (Cuadro 1). En el río Torito se levantaron dos sucesiones (Torito 1: Fig. 5; Torito 2: Fig. 6), y en el Alto de Guayacán una sucesión (Fig. 7), las muestras restantes se consideran aisladas (Fig. 1).

El sedimento fue tratado según el método estándar para la extracción de foraminíferos. Se dejaron las muestras en remojo en agua oxigenada $\left(\mathrm{H}_{2} \mathrm{O}_{2}\right)$ al $10 \%$ durante 24 horas, luego se lavaron y tamizaron por mallas de $45 \mu \mathrm{m}$ y $150 \mu \mathrm{m}$. Se secaron a $40{ }^{\circ} \mathrm{C}$ y de las 2 mallas se almacenó la fracción entre $45 \mu \mathrm{m}$ y $150 \mu \mathrm{m}$, la fracción $>150$ $\mu \mathrm{m}$ se observó al microscopio para determinar la presencia de microfósiles. En todas las muestras se observaron los microfósiles con mucho sedimento, por lo que se procedió nuevamente al remojo con agua oxigenada durante 4 días, luego se lavaron en el baño sónico durante 20 minutos, se tamizaron por la malla $150 \mu \mathrm{m}$ y se repitió el procedimiento hasta observar la muestra limpia. Finalmente la fracción se dejó secar a temperatura ambiente.

La extracción de los foraminíferos bentónicos se realizó en la fracción $>150 \mu \mathrm{m}$. La muestra se dividió utilizando un microcuarteador para asegurar la distribución aleatoria de los especímenes. Se escogió una cuarta parte de la muestra y se procedió a extraer todos los foraminíferos, tanto bentónicos como planctónicos, para utilizar la relación entre ellos y determinar la profundidad relativa. Cuando no se alcanzaron los 300 especímenes, se seleccionó otro cuarto de muestra y se repitió el procedimiento. En algunos casos se aceptaron hasta 109 individuos cuando la muestra no presentaba abundancia de microfósiles.

Para la identificación genérica se siguió a Loeblich \& Tappan $(1964,1988)$ y bibliografía relacionada (Bolli et al., 1964; Cassell, 1986; Cassel \& Sen Gupta, 1989; Collins \& Coates, 1999). Se compararon las especies encontradas con las variables ecológicas y batimétricas actuales. Se calculó el índice de diversidad de Shannon H (logaritmo base 10) utilizando el programa Biodiversity-Pro. Este índice se utiliza en comunidades indefinidamente grandes que no se pueden estudiar en su totalidad, y su valor debe

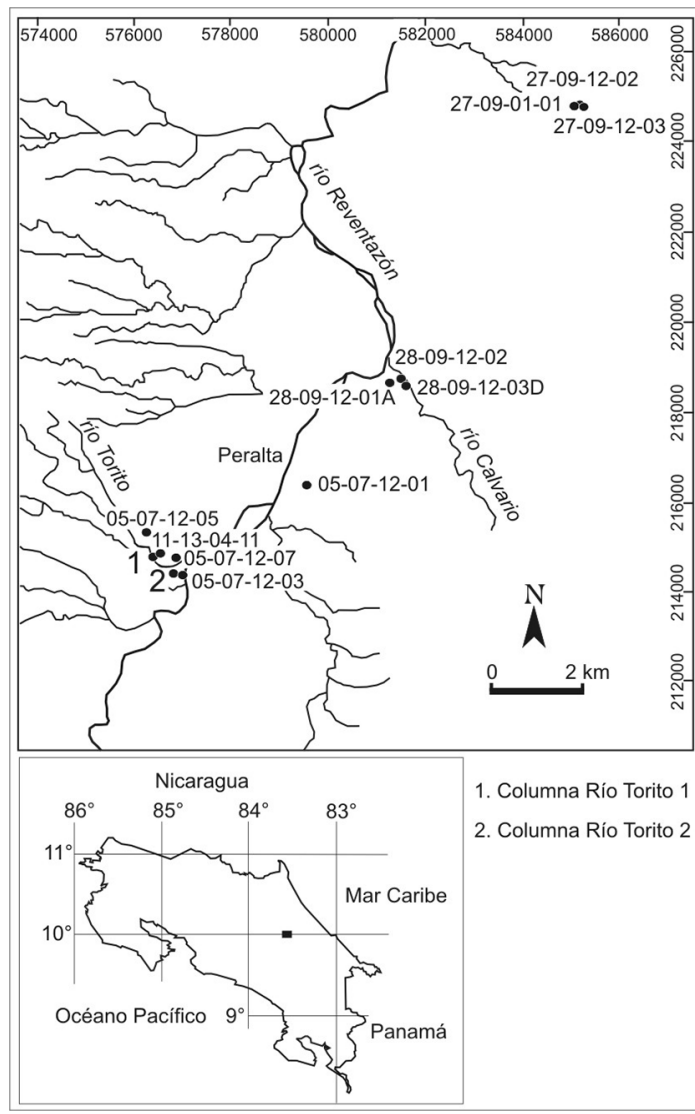

Fig. 1: Ubicación de las muestras analizadas. Río Torito 1: 06-13-04-11, 07-13-04-11, 08-13-04-11, 09-13-04-11, 10-1304-11. Río Torito 2: 05-07-12-09, 05-07-12-11 y 05-07-12-12. Para el Alto de Guayacán la muestra 27-09-12-02 corresponde a la 27-09-12-02 y a la 27-09-12-02B.

estudiarse a partir de una muestra, arrojando un estimado sesgado por cuanto se desconoce el verdadero valor del número de especies en la zona de estudio (Ramírez, 1999). Se realizaron análisis multivariados utilizando el programa Past, disponible en internet (Hammer et al., 2001: http://folk. uio.no/ohammer/past/).

\section{RESULTADOS}

\section{Abundancia y Diversidad}

Los valores de abundancia, número de especies y diversidad de Shannon se presentan en el cuadro 2. Las abundancias se estandarizaron 
Cuadro 1

Ubicación de los sitios de muestreo

\begin{tabular}{|c|c|c|c|}
\hline Código de muestra & Localidad & \multicolumn{2}{|c|}{ Coordenadas ( Costa Rica Lambert Norte) } \\
\hline R. Torito 1 & \multirow{6}{*}{ Río Torito } & \multirow[t]{2}{*}{$\mathrm{X}$} & \multirow[t]{3}{*}{$\mathrm{Y}$} \\
\hline $06 / 13 / 04 / 11$ & & & \\
\hline $07 / 13 / 04 / 11$ & & \multirow{4}{*}{576369,612} & \\
\hline $08 / 13 / 04 / 11$ & & & \multirow[t]{3}{*}{214946,250} \\
\hline $09 / 13 / 04 / 11$ & & & \\
\hline $10 / 13 / 04 / 11$ & & & \\
\hline R. Torito 2 & \multirow{4}{*}{ Río Torito } & & \\
\hline 05-07-12-09 & & 576976,727 & 214517,481 \\
\hline 05-07-12-11 & & \multirow{2}{*}{576848,789} & \multirow{2}{*}{214517,197} \\
\hline $05-07-12-12$ & & & \\
\hline R. Torito & & & \\
\hline $05-07-12-03$ & \multirow{4}{*}{ Río Torito } & 576881,481 & 214885,935 \\
\hline $05-07-12-05$ & & 576258,871 & 215437,560 \\
\hline $05-07-12-07$ & & 576259,752 & 215038,171 \\
\hline $11 / 13 / 04 / 11$ & & 576369,612 & 214946,250 \\
\hline \multicolumn{4}{|l|}{ Peralta } \\
\hline 05-07-12-01 & Peralta & 579543,061 & 216489,525 \\
\hline Guayacán & & & \\
\hline $27-09-12-01$ & \multirow{4}{*}{ Alto Guayacán } & 585111,218 & 225043,575 \\
\hline $27-09-12-02$ & & \multirow{2}{*}{585117,378} & \multirow{2}{*}{225012,866} \\
\hline $27-09-12-02 B$ & & & \\
\hline $27-09-12-03$ & & 585190,540 & 224982,321 \\
\hline Camino $3 \mathrm{X}$ & \multirow{3}{*}{ Tres X Camino } & \multirow{3}{*}{581270,751} & \multirow[b]{2}{*}{218797,715} \\
\hline 28-09-12-01A & & & \\
\hline R. Calvario & & & \\
\hline 28-09-12-02 & \multirow{2}{*}{ Río Calvario } & 581514,185 & 218890,451 \\
\hline 28-09-12-03D & & 581593,732 & 218737,026 \\
\hline
\end{tabular}

a porcentaje para evitar errores debido a que los conteos varían entre 1004 a 109 individuos/ muestra.

\section{Morfología de las conchillas}

Las morfologías de las conchillas en habitats epifaunales bien oxigenados, tienden a ser redondeadas, plano convexas o biconvexas con enrollamiento trocoespiral, con grandes poros que pueden estar ausentes o restringidos a un lado de la conchilla, mientras que los infaunales, generalmente son redondeados planiespirales, cilíndricos globulares u ovalados, ovoides aplanados y con enrollamiento uniserial, triserial o planiespiral y con poros distribuidos en toda la superficie de la conchilla (Corliss \& Chen, 1988).

Los foraminíferos bentónicos pueden clasificarse en morfotipos sobre la base de la forma de la concha y la naturaleza del enrollamiento y pueden relacionarse con la profundidad del agua. Los morfotipos se utilizan para determinar microhabitat, que a su vez puede relacionarse con el 
Cuadro 2

Abundancia, número de especies y diversidad de Shannon $(\mathrm{H})$.

\begin{tabular}{|c|c|c|c|}
\hline Muestra & Abundancia & $\begin{array}{l}\text { Número de } \\
\text { especies }\end{array}$ & $\begin{array}{l}\text { Índice de } \\
\text { Shannon }\end{array}$ \\
\hline \multicolumn{4}{|l|}{ R. Torito 1} \\
\hline $06-13-04-11$ & 656 & 94 & 1,7 \\
\hline 07-13-04-11 & 461 & 73 & 1,5 \\
\hline $08-13-04-11$ & 1004 & 77 & 1,5 \\
\hline 09-13-04-11 & 302 & 57 & 1,5 \\
\hline $10-13-04-11$ & 282 & 16 & 1 \\
\hline \multicolumn{4}{|l|}{ R. Torito 2} \\
\hline 05-07-12-09 & 308 & 23 & 1 \\
\hline $05-07-12-11$ & 223 & 45 & 1,2 \\
\hline $05-07-12-12$ & 413 & 46 & 1,3 \\
\hline \multicolumn{4}{|l|}{ R. Torito } \\
\hline $05-07-12-03$ & 466 & 66 & 1,5 \\
\hline $05-07-12-05$ & 275 & 54 & 1,6 \\
\hline $05-07-12-07$ & 312 & 67 & 1,5 \\
\hline $11-13-04-11$ & 253 & 13 & 0,6 \\
\hline \multicolumn{4}{|l|}{ Peralta } \\
\hline $05-07-12-01$ & 338 & 59 & 1,5 \\
\hline \multicolumn{4}{|l|}{ Guayacán } \\
\hline 27-09-12-01 & 302 & 22 & 1,1 \\
\hline $27-09-12-02$ & 292 & 8 & 0,5 \\
\hline 27-09-12-02B & 109 & 9 & 0,6 \\
\hline $27-09-12-03$ & 333 & 18 & 0,9 \\
\hline \multicolumn{4}{|l|}{ Camino 3X } \\
\hline 28-09-12-01A & 326 & 36 & 1 \\
\hline \multicolumn{4}{|l|}{ R. Calvario } \\
\hline $28-09-12-02$ & 237 & 39 & 1,3 \\
\hline 28-09-12-3D & 257 & 53 & 1,5 \\
\hline
\end{tabular}

contenido de carbono orgánico en los sedimentos superficiales del océano. Las especies se clasificaron según su morfología (cf. Corliss \& Chen, 1988; Kaminski et al., 2005; Murray, 2006). El cuadro 3 muestra los porcentajes totales de los morfotipos epifaunales e infaunales.

\section{Preferencias microambientales y morfología}

Las preferencias microambientales de los foraminíferos no son rígidas; las especies infaunales en particular, parecen ser altamente móviles y capaces de responder a los cambios en las concentraciones de alimento y gradiente de oxígeno, como puede ocurrir en la desembocadura de los ríos, redistribución de la materia orgánica por corrientes, etc. (Gooday, 1994).

Es posible identificar asociaciones recientes de foraminíferos, relacionados con: (1) sedimentos sobreyacidos por aguas de fondo bien oxigenados y morfologías epifaunales, (2) áreas con alta producción de materia orgánica, baja concentración de oxígeno y morfologías infaunales y (3) áreas con alta producción de materia orgánica, independiente de la concentración de oxígeno y morfologías infaunales (Gooday, 1994). Las asociaciones epifaunales bien oxigenadas se hallan en océanos abiertos y pueden a su vez dividirse en: (1) regiones eutróficas, donde los fitodetritos se depositan estacionalmente en grandes proporciones y (2) regiones oligotróficas, menos productivas (Gooday, 1994). Las asociaciones de foraminíferos con alto contenido de materia orgánica y baja concentración de oxígeno, han sido utilizadas para inferir la extensión y evolución de zonas de surgencia en océanos marginales y zonas de oxígeno mínimo durante el Cuaternario (Mullins et al., 1985).

En el modelo Trox (van der Zwaan et al., 1999) interactúan el alimento, el oxígeno y el tipo de hábitat presente dentro o sobre el sedimento. En ambientes oligotróficos (poco alimento y condiciones aeróbicas) hay poca abundancia de especies tanto epifaunales como infaunales someros mientras que en ambientes mesotróficos (el alimento y el oxígeno están balanceados), aumenta la abundancia de foraminíferos y se presentan los dos tipos de hábitat, apareciendo los infaunales profundos. En ambientes eutróficos (altas concentraciones de alimento y condiciones de baja oxigenación o anóxicas), los primeros que desaparecen son los 
morfotipos epifaunales y aumenta el predominio de los morfotipos infaunales profundos. Con lo anterior y teniendo los porcentajes de hábitat epifaunales e infaunales se interpreta el ambiente en el cuadro 3.

\section{Profundidad relativa}

De los conteos finales de foraminíferos planctónicos $(\mathrm{P})$ y bentónicos $(\mathrm{B})$, se calculó la relación P/B. Con base a Brasier (1980), se determina que las relaciones $\mathrm{P} / \mathrm{B}<1$ corresponden a zonas neríticas, mientras que $\mathrm{P} / \mathrm{B}>1$ corresponden a zonas batiales (Cuadro 4). Así, la zona más profunda se habría presentado en la sección $3 \mathrm{X}$, seguido por las secciones Alto Guayacán, Río Calvario y la parte inferior de la sección de Río Torito 1. Las muestras restantes se habrían depositado en zonas neríticas o litorales.

\section{Salinidad}

El diagrama de Brasier (1980) se utiliza para inferir condiciones de salinidad (Fig. 2). Las asociaciones de ciénagas y manglares se caracterizan por contener un $100 \%$ de textulariina (aglutinados) en ciénagas alejadas a la costa, en comparación con las formas rotaliina (hialinos) que caracterizan ciénagas cercanas a la costa. En el diagrama ternario, las ciénagas y estuarios salubres están localizadas en el lado textulariina - rotaliina, y las ciénagas hipersalinas en el lado rotaliina - miliolina (porcelanaceos). Muestras marinas normales e hipersalinas están en el lado rotaliina - miliolina, con cantidades variables de aglutinados (Murray, 2006).

Debido al alto porcentaje de lageninos, se graficó junto con rotaliina y textulariina, (Fig. 2). Los lageninos se interpretan como de condiciones de plataforma con niveles de salinidad y oxígeno normales (Nagy \& Seidenkrantz, 2003). Las muestras que presentaron salinidades afines con ambientes de plataforma fueron las ubicadas en la
Cuadro 3

Morfología y ambiente.

\begin{tabular}{|c|c|c|c|}
\hline \multirow{2}{*}{ Muestras } & \multicolumn{2}{|c|}{ Hábitat (\% total) } & \multirow{2}{*}{ Ambiente } \\
\hline & Epifaunal & Infaunal & \\
\hline \multicolumn{4}{|l|}{ R. Torito 1} \\
\hline 06-13-04-11 & 32,9 & 61 & Eutrófico \\
\hline $07-13-04-11$ & 41,8 & 35,6 & Mesotrófico \\
\hline 08-13-04-11 & 25,6 & 68 & Eutrófico \\
\hline 09-13-04-11 & 49,0 & 37,4 & Mesotrófico \\
\hline $10-13-04-11$ & 75,2 & 20,6 & Oligotrófico \\
\hline \multicolumn{4}{|l|}{ R. Torito 2} \\
\hline 05-07-12-09 & 68,8 & 20,2 & Oligotrófico \\
\hline $05-07-12-11$ & 67,6 & 28,3 & Oligotrófico \\
\hline $05-07-12-12$ & 54,0 & 33,4 & Oligotrófico \\
\hline \multicolumn{4}{|l|}{ R. Torito } \\
\hline $05-07-12-03$ & 50,2 & 42,1 & Mesotrófico \\
\hline $05-07-12-05$ & 57,8 & 31,6 & Oligotrófico \\
\hline $05-07-12-07$ & 73,0 & 24,6 & Oligotrófico \\
\hline 11-13-04-11 & 89,3 & 9,1 & Oligotrófico \\
\hline \multicolumn{4}{|l|}{ Peralta } \\
\hline $05-07-12-01$ & 69,1 & 30,1 & Oligotrófico \\
\hline \multicolumn{4}{|l|}{ Guayacán } \\
\hline 27-09-12-01 & 78,5 & 12,3 & Oligotrófico \\
\hline 27-09-12-02 & 84,9 & 0 & Oligotrófico \\
\hline $27-09-12-02 B$ & 84,4 & 0 & Oligotrófico \\
\hline $27-09-12-03$ & 67,6 & 26,7 & Oligotrófico \\
\hline \multicolumn{4}{|l|}{ Camino 3X } \\
\hline $28-09-12-01 \mathrm{~A}$ & 57,5 & 41,4 & Mesotrófico \\
\hline \multicolumn{4}{|l|}{ R. Calvario } \\
\hline $28-09-12-02$ & 50,2 & 40,9 & Mesotrófico \\
\hline $28-09-12-3 \mathrm{D}$ & 52,9 & 42,0 & Mesotrófico \\
\hline
\end{tabular}

sección de Guayacán, disminuyendo en las muestras de las secciones de Río Torito 1 (zona batial) y Río Calvario. Las otras muestras habrían sido el resultado de la combinación de ambientes entre plataforma con niveles normales de salinidad y ciénagas-estuarios salobres. 
Cuadro 4

Profundidad relativa (relación P/B).

\begin{tabular}{|c|c|c|}
\hline Muestras & $\mathrm{P} / \mathrm{B}$ & Profundidad relativa \\
\hline \multicolumn{3}{|l|}{ R. Torito 1} \\
\hline $06-13-04-11$ & 2,3 & Batial \\
\hline $07-13-04-11$ & 1,1 & Batial \\
\hline 08-13-04-11 & 3 & Batial \\
\hline 09-13-04-11 & 3 & Batial \\
\hline $10-13-04-11$ & 0 & Nerítica \\
\hline \multicolumn{3}{|l|}{ R. Torito 2} \\
\hline 05-07-12-09 & 0 & Nerítica \\
\hline $05-07-12-11$ & 0 & Nerítica \\
\hline $05-07-12-12$ & 0 & Nerítica \\
\hline \multicolumn{3}{|l|}{ R. Torito } \\
\hline $05-07-12-03$ & 0,3 & Nerítica \\
\hline $05-07-12-05$ & 0,6 & Nerítica \\
\hline $05-07-12-07$ & 0,3 & Nerítica \\
\hline $11-13-04-11$ & 0 & Nerítica \\
\hline \multicolumn{3}{|l|}{ Peralta } \\
\hline 05-07-12-01 & 0,5 & Nerítica \\
\hline \multicolumn{3}{|l|}{ Guayacán } \\
\hline 27-09-12-01 & 6,6 & Batial \\
\hline $27-09-12-02$ & 13,4 & Batial \\
\hline 27-09-12-02B & 6,3 & Batial \\
\hline 27-09-12-03 & 7,2 & Batial \\
\hline \multicolumn{3}{|l|}{ Camino 3X } \\
\hline 28-09-12-01A & 14 & Batial \\
\hline \multicolumn{3}{|l|}{ R. Calvario } \\
\hline $28-09-12-02$ & 4,7 & Batial \\
\hline $28-09-12-3 \mathrm{D}$ & 5,8 & Batial \\
\hline
\end{tabular}

\section{Análisis multivariados}

Para efectuar los análisis multivariados, se escogieron los porcentajes mayores o iguales a $4,5 \%$ de especies que estuvieran presentes en al menos 2 muestras.

\section{Análisis de agrupamiento (Cluster)}

Con el análisis de agrupamiento se determinan asociaciones de muestras relacionadas entre sí, según la "distancia del vecino más cercano" (distancia euclidiana de 20), donde el agrupamiento se realiza entre la menor distancia (mayor similaridad) entre los grupos y dando el mismo peso a cada uno de los datos en cada agrupamiento (Fig. 3). De las 20 muestras se determinaron 6 grupos de agrupamiento, donde la relación o similitud entre ellas fueron debidas a la profundidad, ambiente, diversidad y especie (s) dominante (s). Los grupos y su interpretación se presentan a continuación:

Grupo I: Representa una zona nerítica, mesotrófica, diversidad igual $(1,5)$ y la especie Pararotalia sp.

Grupo II: Representa una combinación entre la zona batial y la nerítica, transición de ambientes desde eutrófico hasta oligotrófico, diversidad similar (entre 1,5 y 1,7 ) y las especies Uvigerina flinti y Pararotalia sp.

Grupo III: Representa combinación entre la zona batial y la nerítica y las especies Pararotalia sarmientoi. Cibicidoides falconensis, Melonis pompilioides y Planorbulina mediterranis. Este grupo presenta especies de mayor profundidad que las presentes en el grupo II.

Grupo IV: Especie P. sarmientoi.

Grupo V: Representa una zona batial, salinidad con ambientes de plataforma oligotrófica, y la menor diversidad de las muestras (entre 0,5 y 0,9), y las especies Lenticulina calcar y L. occidentalis, Saracenaria latifrons, Valvulineria sp., у C. falconensis.

Grupo VI: Representa una zona nerítica y las especies Lepidocyclina sp., Heterostegina sp., y P. sarmientoi. Este grupo se diferencia del grupo I, en que debieron existir sustratos duros debido a la presencia de macroforaminíferos (arrecifes).

\section{Análisis de componentes principales}

Se realizó el análisis de componentes principales (PCA, Principal Component Analysis), el cuál determina variables hipotéticas (componentes) que respondan o expliquen en la medida de lo posible la variación de los datos presentados. Se utiliza la matriz varianza-covarianza cuando todos los datos están en las mismas unidades, en 


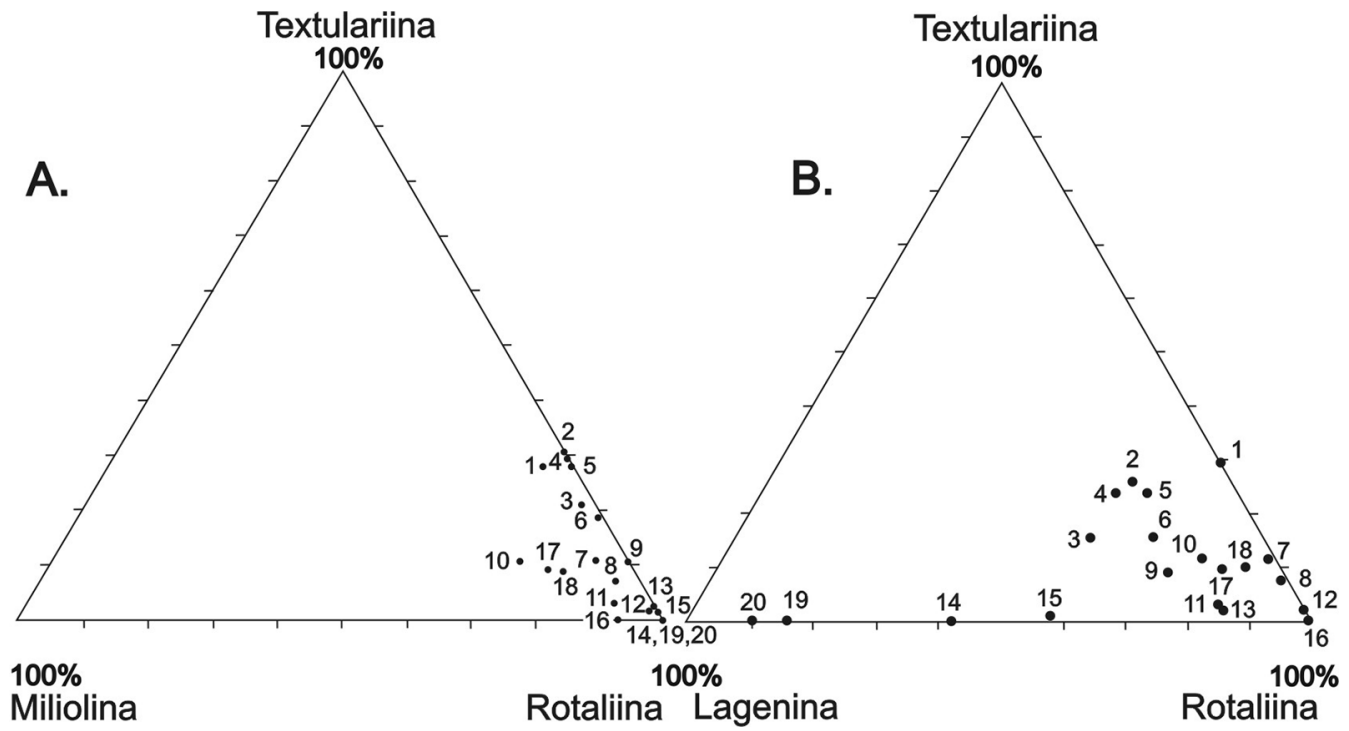

Fig. 2: Diagrama ternario de Brasier (1980). A) Porcentaje de foraminíferos textulariina (aglutinados), rotaliina (hialinos) y miliolina (porcelanaceos). B) Porcentaje de foraminíferos textulariina (aglutinados), rotaliina (hialinos) y lageninos. Muestras: (1) 10-13-04-11. (2) 07-13-04-11. (3) 06-13-04-11. (4) 09-13-04-11. (5) 28-09-12-3D. (6) 08-13-04-11. (7) 05-07-12-11. (8) 05-07-12-12 . (9) 05-07-12-01. (10) 28-09-12-02. (11) 05-07-12-03. (12) 11-13-04-11 . (13) 28-09-12-01A. (14) 27-09-12-03. (15) 27-09-12-01 . (16) 05-07-12-09. (17) 05-07-12-05. (18) 05-07-12-07. (19) 27-09-12-02 . (20) 27-09-12-02B.

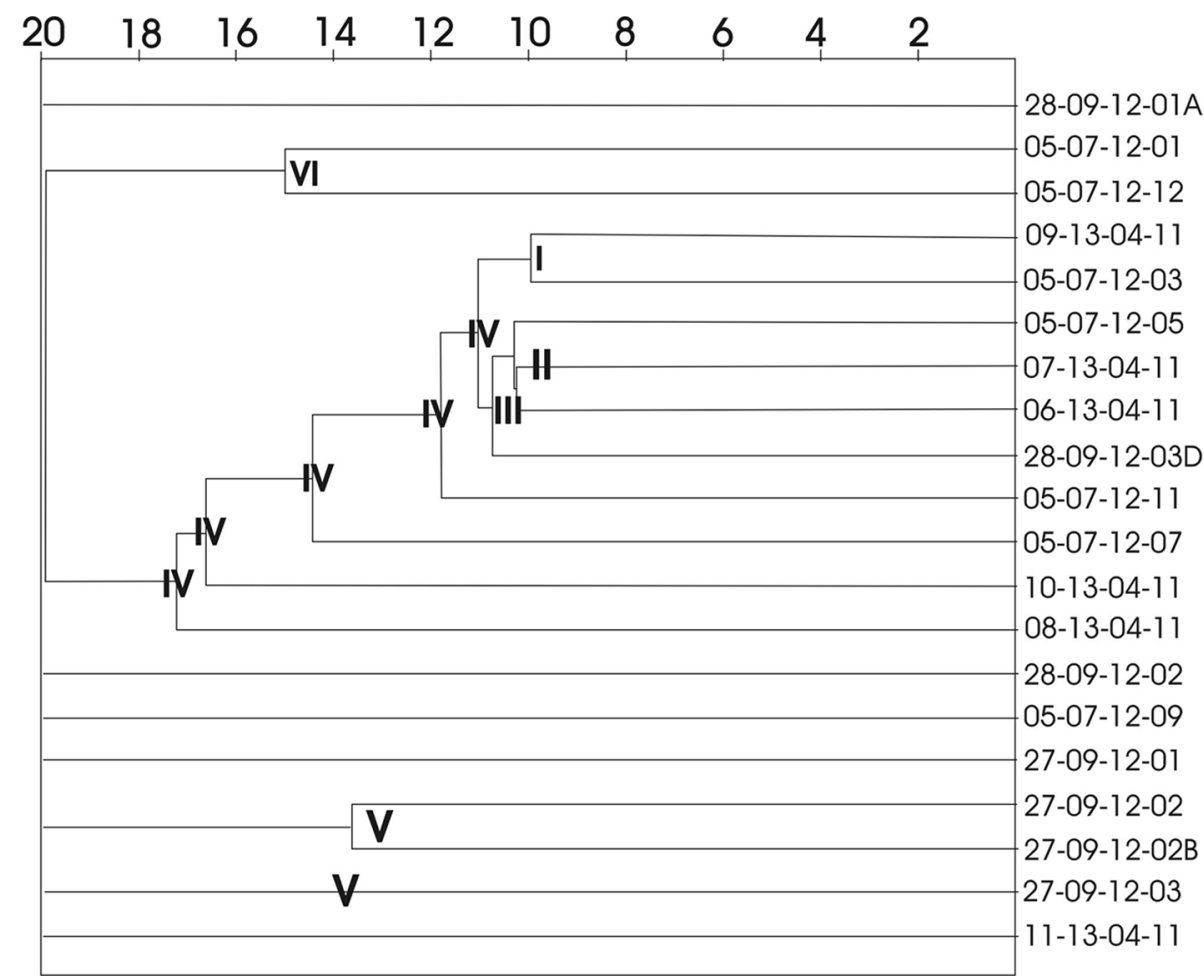

Fig. 3: Análisis de agrupamiento (cluster) modo Q (muestras). Se enumeran los grupos desde la mayor similitud (I) hasta la menor (VI). 
este caso porcentaje. Los "eigenvalues" (peso-importancia), son una medida de la varianza calculada para cada uno de los componentes. También se presentan los porcentajes de la varianza calculada para cada uno de los componentes (PC). Se considera exitoso el PCA, si los porcentajes de la varianza se explican entre 1 a 3 componentes, si el porcentaje está distribuido uniformemente entre todos los componentes, el PCA no debe ser utilizado (Hammer, et al., 2001).

Los tres primeros componentes (de 19 que calculó el programa) explican el $81 \%$ de la variación de los datos, donde el PC-1 explica el $45 \%$ de la variabilidad, el PC-2 el 27\% y el PC-3 el 9\%, con un peso de 486, 293 y 100 respectivamente. Para este caso se utilizan los dos primeros componentes. En el cuadro 5, se enumeran los dos componentes con las varianzas tanto de las muestras (loadings) como de las especies (scores). Las muestras que tienen mayor importancia en la explicación del PC-1 son: 27-09-12-01, 27-09-12-02, 27-09-12-02B, 27-0912-03 (zonas batiales) y 05-07-12-09 (zona nerítica) con índice negativo (Cuadro 5). Para el PC-2: 11-13-04-11, 05-07-12-09, 05-07-12-12 y 10-1304-11, todas neríticas y con índices positivos.

Las especies que son importantes para explicar el primer componente, PC-1 son (Fig. 4): $L$. calcar (con un valor 3 veces mayor). Las otras especies presentan índices negativos, Lepidocyclina sp., S. latifrons, Pararotalia sp., y P. sarmientoi. El género Lenticulina es de aguas frías en plataformas externas y batiales (Murray, 2006). Lenticulina abreviada L. calcar, se encuentra en la plataforma de México y es importante en las muestras con profundidad batial (secciones Río Calvario: 3D; camino 3X: 01A y Guayacán: 01, 02, 02B y 03). Lepidocyclina sp., es nerítica, vive asociada a arrecifes corales-algas oligotróficos y ambientes someros carbonatados (Murray, 2006). En la Formación Uscari es importante en todas las muestras del Río Torito y en mayor proporción en el estrato de calcilutitas amarillas.

El género Pararotalia habita zonas litorales $(0-20 \mathrm{~m})$ en condiciones agitadas, con sustrato arenoso (Murray, 2006). P. sarmientoi, se encuentra en todas las muestras con excepción del Alto de Guayacán. En las muestras batiales se presenta como especie minoritaria aumentando en las zonas neríticas hasta alcanzar un $12 \%$ (Cuadro 5, Fig. 4). Por lo anterior se considera que el componente PC-1 representa una asociación que habitaba la zona batial con aportes de especies de plataforma y litorales transportadas por corrientes de turbidez (grupo II, III del análisis de agrupamiento).

El componente PC-2: Lepidocyclina sp., $L$. calcar, Pararotalia sp. y Anomalinoides io con índice negativo (Cuadro 5, Fig. 4) se considera nerítico, ya que todas las muestras que corresponden a esa zona tienen los mayores valores (grupo I y VI del análisis de agrupamiento).

\section{Paleobatimetría y paleoecología}

Se levantaron las sucesiones sedimentarias de Río Torito 1, Río Torito 2 y Guayacán, las otras muestras se consideran aisladas (Fig. 1). La sucesión Río Torito 1 (Fig. 5) está constituida por lutitas calcáreas con laminación paralela, horizontal y estructuras de flujo. Se considera Mioceno Temprano por la presencia de Lepidocyclina sp. (Loeblich \& Tappan, 1989), Lagena gibbera y Cibicidoides falconensis (Bolli et al., 1964). Según la relación $\mathrm{P} / \mathrm{B}$ se interpreta una somerización hacia el tope de la sucesión desde profundidades batiales hasta neríticas. El componente PC-1 no es importante pero muestra un ligero aumento en la zona batial. El componente PC-2 es importante hacia la parte superior de la sucesión (Fig. 6). 
Cuadro 5

Análisis de componentes principales.

\begin{tabular}{|c|c|c|c|c|c|}
\hline & $\mathrm{PC}-1$ & $\mathrm{PC}-2$ & & $\mathrm{PC}-1$ & $\mathrm{PC}-2$ \\
\hline Peso cada PC & 486 & 293 & Peso cada PC & 486 & 293 \\
\hline Porcentaje & 45 & 27 & Porcentaje & 45 & 27 \\
\hline$\%$ acumulado & 45 & 72 & $\%$ acumulado & 45 & 72 \\
\hline Muestras & "Loading" & Especies & "Scores" & & \\
\hline R. Torito 1 & & & Lenticulina calcar & 86,4 & 19,7 \\
\hline $06-13-04-11$ & $-0,3$ & 0,2 & Lenticulina occidentalis & 5,2 & $-4,3$ \\
\hline $07-13-04-11$ & $-0,3$ & 0,3 & Saracenaria latifrons & 14,2 & $-2,0$ \\
\hline 08-13-04-11 & $-0,2$ & 0,0 & Lepidocyclina sp. & $-27,7$ & 64,8 \\
\hline $09-13-04-11$ & $-0,2$ & 0,2 & Siphogenerina smithi & $-5,8$ & $-8,5$ \\
\hline $10-13-04-11$ & $-0,3$ & 0,5 & Siphogenerina transversa & $-1,3$ & $-7,6$ \\
\hline R. Torito 2 & & & Uvigerina sp. & $-5,7$ & $-8,7$ \\
\hline 05-07-12-09 & $-0,4$ & 0,9 & Anomalinoides io & $-5,0$ & $-12,8$ \\
\hline $05-07-12-11$ & $-0,2$ & 0,1 & Valvulineria sp. & 7,0 & $-4,8$ \\
\hline $05-07-12-12$ & $-0,3$ & 0,7 & Valvulineria palmerae & $-0,4$ & $-6,9$ \\
\hline R. Torito & & & Cibicidoides falconensis & 3,4 & $-5,4$ \\
\hline $05-07-12-03$ & $-0,2$ & 0,3 & Melonis pompilioides & $-6,1$ & $-7,3$ \\
\hline 05-07-12-05 & $-0,1$ & 0,0 & Uvigerina flinti & $-6,9$ & $-7,4$ \\
\hline 05-07-12-07 & $-0,3$ & 0,2 & Heterostegina sp. & $-8,6$ & $-0,3$ \\
\hline 11-13-04-11 & $-0,3$ & 0,9 & Cibicides floridanus & $-5,2$ & $-8,5$ \\
\hline Peralta & & & Planorbulina mediterranensis & $-6,3$ & $-6,7$ \\
\hline 05-07-12-01 & $-0,3$ & 0,4 & Elphidium sp1 & $-6,3$ & $-6,0$ \\
\hline Guayacán & & & Ammonia sp. & $-5,6$ & $-6,1$ \\
\hline 27-09-12-01 & 0,7 & 0,0 & Pararotalia sarmientoi & $-12,0$ & 8,4 \\
\hline $27-09-12-02$ & 1,0 & 0,2 & Pararotalia $\mathrm{sp.}$ & $-13,3$ & 10,3 \\
\hline 27-09-12-02B & 1,0 & 0,2 & & & \\
\hline $27-09-12-03$ & 0,9 & 0,2 & & & \\
\hline \multicolumn{6}{|l|}{ Camino $3 \mathrm{X}$} \\
\hline $28-09-12-01 \mathrm{~A}$ & 0,0 & $-0,2$ & & & \\
\hline \multicolumn{6}{|l|}{ R. Calvario } \\
\hline $28-09-12-02$ & $-0,1$ & $-0,2$ & & & \\
\hline 28-09-12-3D & 0,1 & $-0,2$ & & & \\
\hline
\end{tabular}

Los valores en negrita corresponden a las muestras y especies representativas para cada PC 


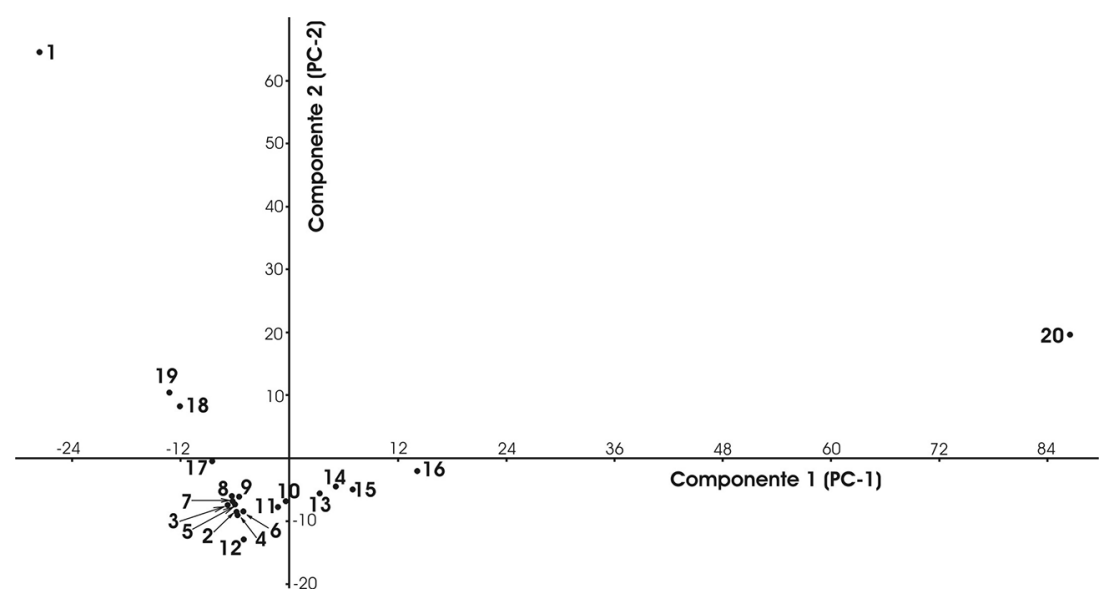

Fig. 4: Los componentes (eigenvectors), PC-1 y PC-2, son perpendiculares y forman un sistema de coordenadas espaciales, donde los eigenvalue dan una medida de la importancia de cada eje en las especies. Los números corresponden a: 1. Lepidocyclina sp.; 2. Siphogenerina smithi; 3. Uvigerina flinti; 4. Uvigerina sp.; 5. Melonis pompilioides; 6. Cibicides floridanus; 7. Planorbulina mediterranensis; 8. Elphidium sp1.; 9. Ammonia sp.; 10. Valvulineria palmerae; 11. Siphogenerina transversa; 12. Anomalinoides io; 13. Valvulineria sp.; 14. Lenticulina occidentalis; 15. Cibicidoides falconensis; 16. Saracenaria latifrons; 17. Heterostegina sp.; 18. Pararotalia sarmientoi; 19. Pararotalia sp.; 20. Lenticulina calcar.

La interpretación de profundidades batiales (parte inferior y media de la sección) está apoyada por la presencia de Melonis pompilioides, Cibicides wellerstorfi, Cassidulina subglobosa, Siphogenerina transversa, Gyroidina soldanii y Pullenia bulloides; mientras que las profundidades neríticas y litorales $(<10 \mathrm{~m})$ está apoyada por la presencia de las especies U. flinti, Elphidium gunteri, $P$. mediterranensis y $P$. sarmientoi, hacia el tope de la sección.

La combinación de ambientes desde eutrófico a mesotrófico en la zona batial, está apoyada por la presencia de pirita y minerales metálicos que se encuentran como moldes internos o en las suturas de las conchas. Adicionalmente en muchos horizontes el color gris cambia a casi negro, posiblemente por el alto contenido de materia orgánica. La laminación horizontal sin bioturbación es otra evidencia del bajo contenido de oxígeno en el fondo. Por lo tanto, se considera que la parte inferior de la sucesión fue depositada bajo condiciones de surgencia oceánica.

La parte nerítica es considerada como el producto de condiciones oligotróficas con sustratos duros, de alta energía y aguas cálidas. La muestra 10-13-04-11, presento altos contenidos de cuarzo. La diversidad para esta muestra disminuye a 1 .
La sucesión del Río Torito 2 (Figs. 7 y 8), está constituida de lutitas calcáreas con intercalaciones de lentes de arena y calcarenitas, y en su parte superior bioturbación y un estrato de conglomerado. La estratificación es horizontal, con laminaciones paralelas en su parte inferior y homogénea por bioturbación en la parte media y superior. Se considera Mioceno Temprano por la ocurrencia de Lepidocyclina sp., aunque no aparecen Lagena gibbera ni Cibicidoides falconensis, debido a que son especies batiales.

Según la relación $\mathrm{P} / \mathrm{B}$ se interpreta como una zona nerítica a litoral. El componente PC-1 no es importante, en comparación con el componente PC-2 que presenta los mayores valores. La interpretación de la paleobatimetría nerítica a litoral está apoyada por la presencia de $P$. sarmientoi, Amphistegina gibbosa, Miniacina sp., Calcarina sp., Ammonia sp., Elphidium sp. y Heterostegina sp.

El paleoambiente es interpretado como oligotrófico, de borde de arrecife protegido de las olas, como lo sugiere C. calcar que se esconde entre las algas para evitar la luz (Murray, 2006), de alta energía y sustratos arenosos y duros, y aguas cálidas. Presenta alto contenido de cuarzo angular. $\mathrm{La}$ diversidad es relativamente constante. 


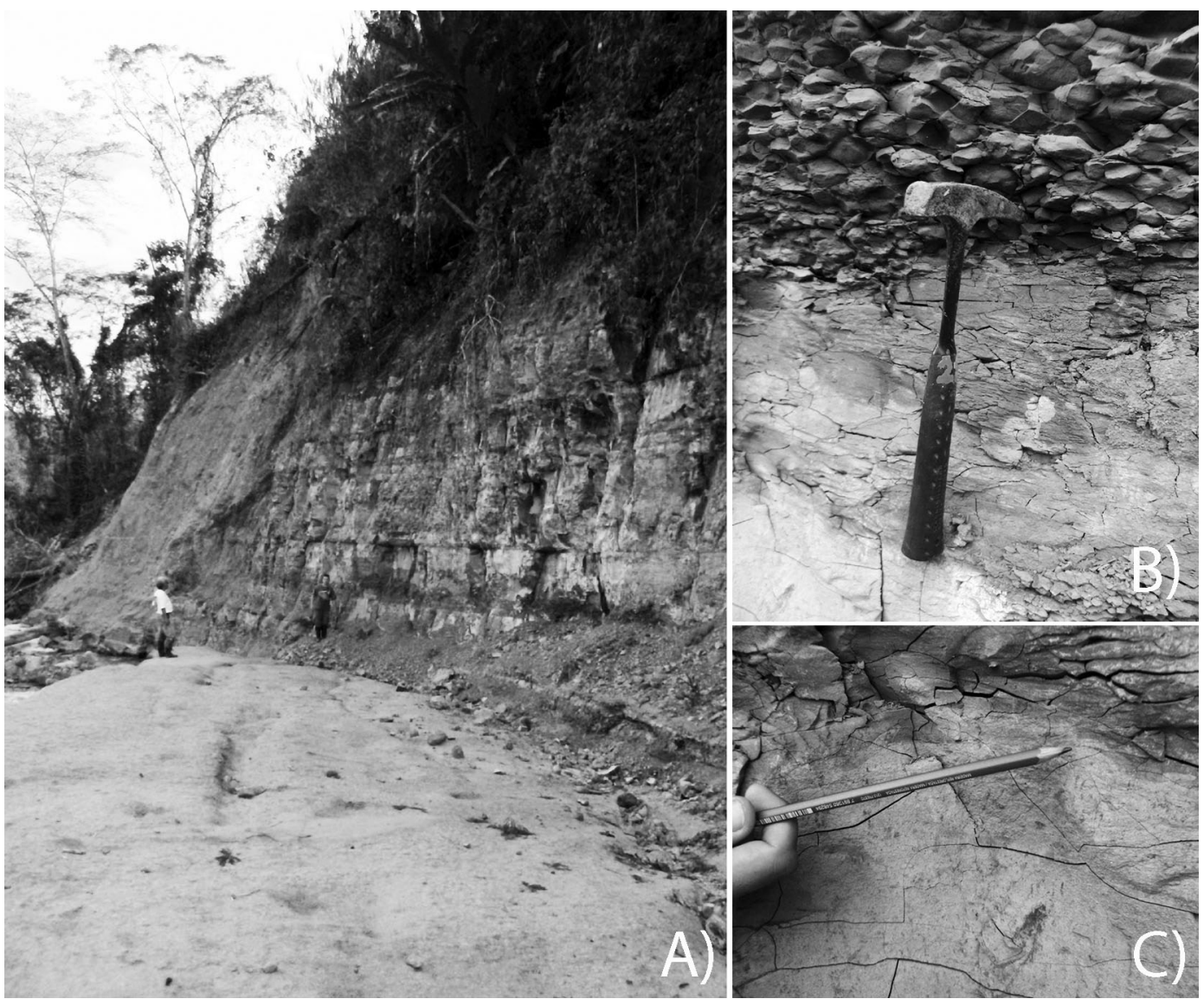

Fig. 5: Vista general de la sucesión del Río Torito 1 (A). Lutitas calcáreas con colores gris claro a oscuro. Laminación horizontal y con apariencia de concreciones solo superficiales (B). Estructuras de flujo (C).

En río Torito se extrajeron las muestras 0507-12-03, 05-07-12-05, 05-07-12-07 del Mioceno Temprano y la muestra 11-13-04-11, sin datación. Todas las muestras presentan valores bajos y negativos para el componente PC-1 y valores positivos para el componente PC-2, siendo la muestra 11-13-04-11 la de mayor valor. La muestra 05-0712-05 es arenosa con abundancia de biotita, de alta energía, nerítico abierto, y presenta especies de plataforma como U. flinti, C. floridanus, $M$. pompilioides, L. calcar y especies someras como P. mediterranensis, C. calcar y P. sarmientoi. Las muestras 05-07-12-03, 05-07-12-07 y 11-13-0411 , son litorales, con madera, abundancia de cuarzo, plagioclasa angular, magnetita, fragmentos de roca, ostrácodos articulados y desarticulados, icnitas y ocasionalmente pirita. Las especies son
Ammonia sp., P. sarmiento, C. calcar, A. gibbosa $\mathrm{y}$ en menor proporción $U$. flinti. La muestra 0507-12-03 es mesotrófica, las demás muestras son oligotróficas. Las diversidades son constantes a excepción de la muestra 11-13-04-11, que presenta la diversidad más baja.

La muestra 05-07-12-01 ubicada en Peralta, cerca del río Reventazón, es del Mioceno Temprano, nerítica y oligotrófica. El componente PC-2 es importante y positivo, mientras que el componente $\mathrm{PC}-1$ es negativo y de menor valor. Las especies dominantes son someras, $P$. sarmientoi $(10.9 \%)$, Heterostegina sp. (17.5\%) y P. mediterranensis (1.8\%). Adicionalmente se observaron fragmentos de espinas de erizos y conchas.

La muestra 28-09-12-01A está ubicada en 3X cerca al río Calvario, es del Mioceno Temprano, 


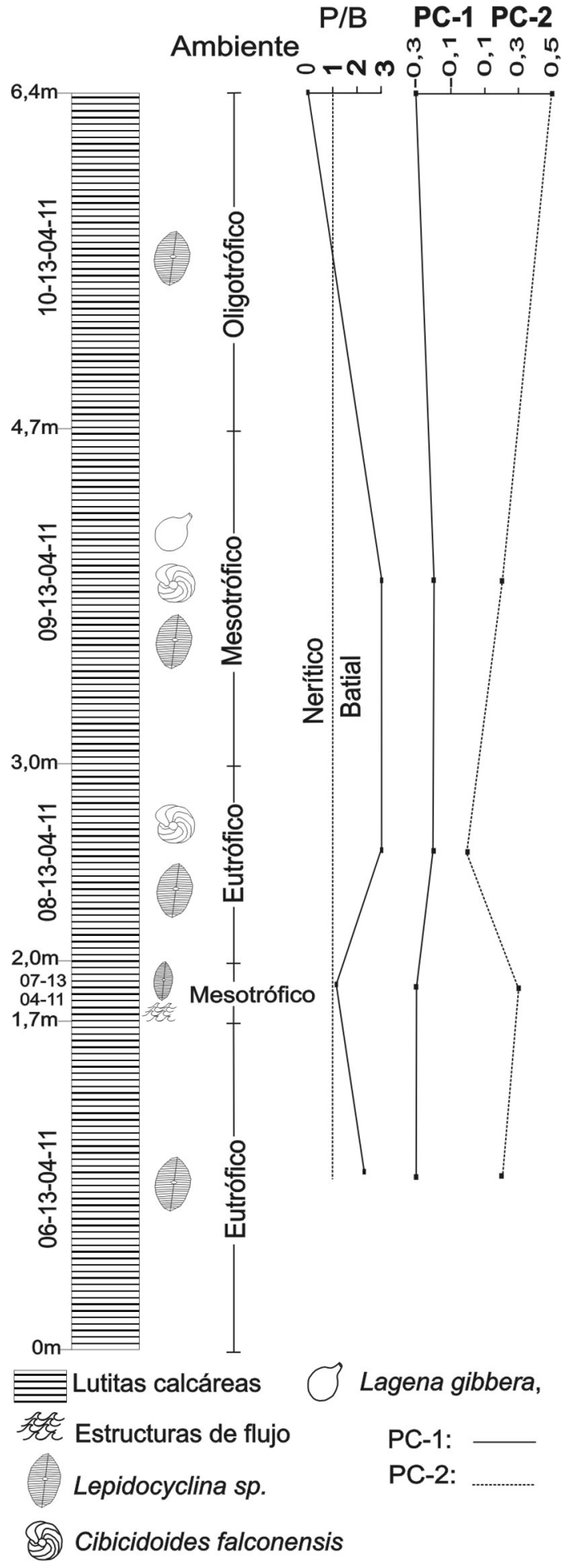

es la más profunda de las muestras (batial inferior hasta $4000 \mathrm{~m}$ ) que corresponden a esta sección, es mesotrófica y su diversidad es la menor entre las muestras que representan profundidades batiales. Los componentes no son importantes, debido a que uno representa mezcla de especies y el otro ambiente somero. A pesar de la profundidad no parece presentar procesos de resedimentación, debido a que las especies infaunales profundas reflejan zonas estables, en este caso la especie Globobulimina perversa presenta abundancias hasta del 4\%. Las especies más importantes son L. calcar, L. occidentalis, S. transversa, Sphaeroidina bulloides, Uvigerina hispido costata. El género Uvigerina (6.1\% de la muestra) en la zona batial media inferior y superior inferior, presenta costillas que tienden a cortarse en segmentos cortos y espinas, características que se observan en las especies encontradas para este género (Bergen \& O’Neil, 1979).

Las muestras 28-09-12-03D y 28-09-12-02, se ubican en el río Calvario en márgenes opuestas. La primera corresponde al Mioceno Temprano y la segunda al Mioceno Medio por la presencia de la Orbulina universa (Bolli et al, 1985), por lo que el río Calvario representaría el contacto entre el Mioceno Temprano y el Mioceno Medio. Las muestras anteriores son batiales y mesotróficas y la diversidad es constante. Los componentes no son importantes por las mismas razones expuestas para la muestra anterior (mezcla de especies y ambiente somero), aunque sí presentan especies someras como la P. mediterranensis, P. sarmientoi, Cymbaloporetta sp. (12,1\% en la muestra 2812-03D). También se observan espinas de erizos, fragmentos de coral (4 especies diferentes, entre ellos uno reticulado), fragmentos de ostrácodos y miliolidos. Adicionalmente se encuentra montmorillonita, arcilla de origen volcánico (Barahona et al., 2012).

Fig. 6: Sucesión del Río Torito 1. Paleobatimetría indicado por la relación P/B, sistema trófico (Van der Zwaan et al., 1999) $\mathrm{y}$ asociaciones microfaunales (componentes principales PC-1 y PC-2). Se considera Mioceno Temprano (Aquitaniense), por la última aparición de Lepidocyclina sp. (Loeblich \& Tappan, 1989) y primera aparición de Lagena gibbera y Cibicidoides falconensis (Bolli et al., 1964). 

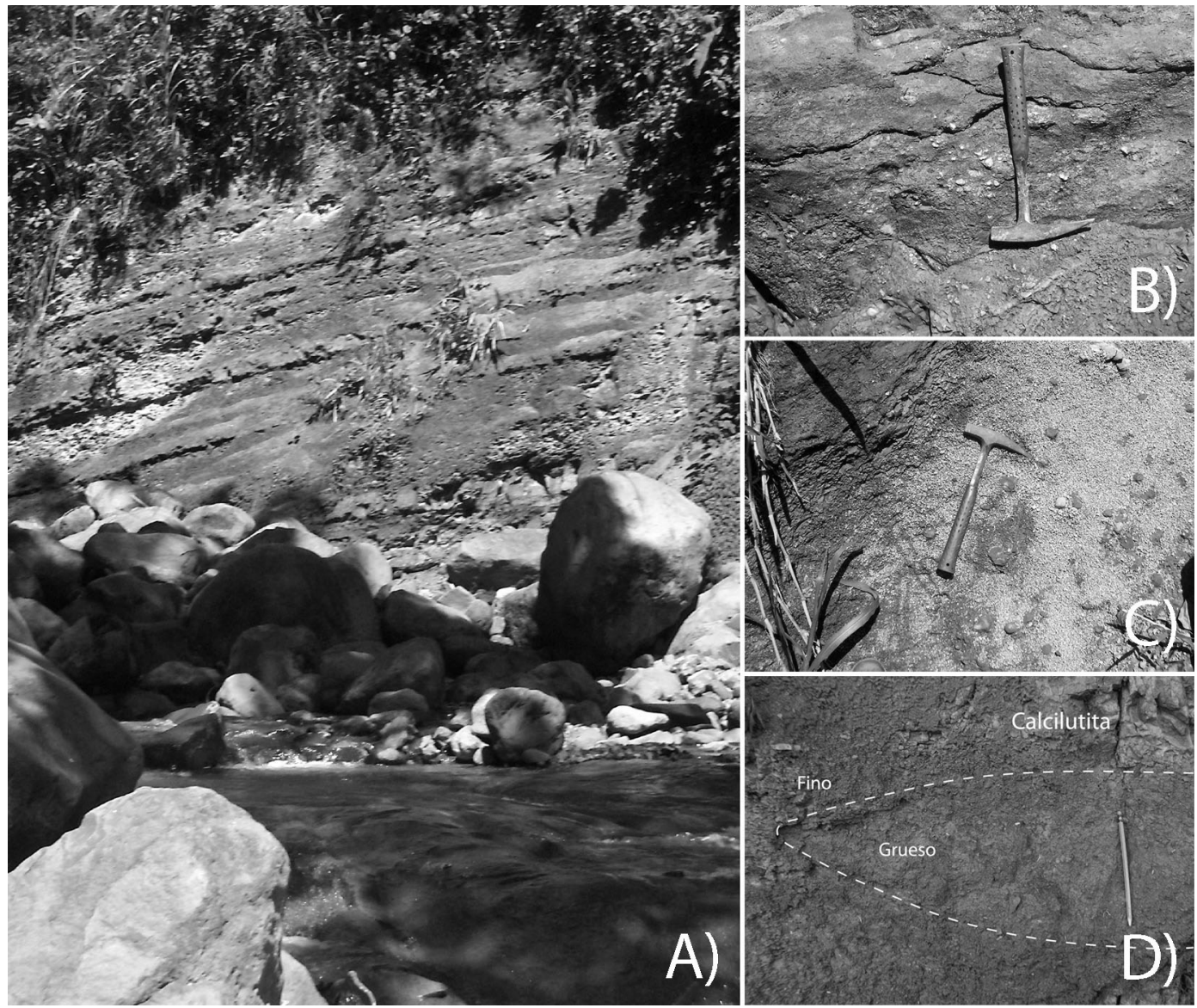

Fig. 7: Sucesión del Río Torito 2. Vista general de la secuencia (A). Lutitas calcáreas, con intercalaciones de lentes arenosos y calcarenitas o calcilutitas amarillas de gran dureza, en forma de estratos continuos o como concreciones elípticas (D). Conglomerado (B) o zona de rompiente con fragmentos de caliza, corales, vermétidos y espinas de erizos. La parte superior presenta bioturbación Thalassinoides isp. (C).

La última sucesión corresponde al Alto Guayacán (Fig. 9) con edad relativa del Mioceno Medio, profundidad batial y ambiente oligotrófico. La diversidad es menor a mayor profundidad (en la sección media de la sucesión), y es la menor de todas las muestras recolectadas, debido posiblemente a la alta predación y a la falta de nutrientes. Los valores para el componente PC-1, son los mayores de todas las muestras y para el componente PC-2 los valores son menores pero importantes. Las especies someras del género Ammonia sp., representan abundancias hasta el
$4.6 \%$, la especie dominante es la $L$. calcar, con abundancias desde $15,6 \%$ a $63 \%$. Se observaron fragmentos de espinas de erizos, Anadara sp., y ostrácodos desarticulados.

Los estudios realizados por Laurito (1996; 1999) para el Alto de Guayacán incluyen dientes de tiburones (especie de tiburón IsistiusSqualidae), rayas e ictiolitos, con amplia distribución tropical y habitante común de ambientes pelágicos (aguas intermedias). La edad de los sedimentos es Mioceno Tardío Terminal, límite Messiniense-Zancliense o zona de foraminíferos plantónicos N-17-19, según Pizarro (1985). 


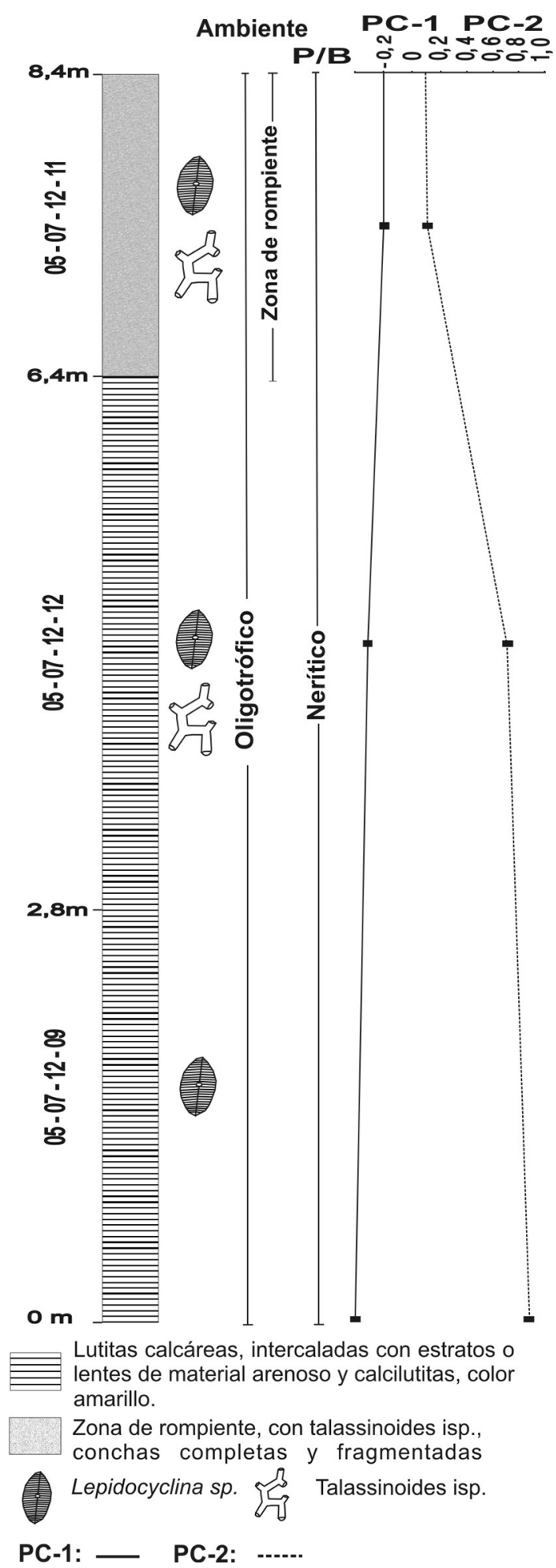

\section{DISCUSIÓN}

En el área de estudio, la Formación Uscari en el Mioceno Temprano, muestra una somerización desde zonas batiales inferiores a neríticas, cambiando nuevamente a zonas batiales durante el Mioceno Medio.

Aunque no se puede hacer una correlación definitiva entre las sucesiones observadas en Torito 1 y Torito 2 hasta realizar un análisis bioestratigráfico (foraminíferos planctónicos), para esta discusión se asume que la sucesión Río Torito 2 y las muestras aisladas de Río Torito y Peralta corresponden a la somerización que se observa hacia el final de la sucesión Río Torito 1. Las zonas más profundas de esta investigación corresponde a $3 \mathrm{X}$, la cual alcanza profundidades batiales inferiores con una población estable sin corrientes de turbidez, le siguen Guayacán, río Calvario y la parte inferior de Río Torito 1, afectadas por corrientes de turbidez con especies someras de ambientes de alta energía, asociados a arrecifes coralinos y de algas, sustratos duros y arenosos, algunas de las cuales presentaban muy mala preservación como es el caso de Lepidocyclinas sp., Heterosteginas sp. y Elphidium sp., mezcladas con especies batiales y de plataforma, y afectados por surgencia oceánica.

Durante el Mioceno Medio, ocurre una profundización hasta zonas batiales, que corresponde al Alto de Guayacán, nuevamente afectada por corrientes de turbidez y con ambientes oligotróficos.

La zona batial del área de estudio se correlaciona con las zonas batiales presentes en parte inferior de la quebrada Terciopelo y el Mioceno Temprano del río Reventazón, esta última alcanzando la zona abisal, las cuales estuvieron sujetas a flujos de turbidez y a la introducción de taxas someras en agua profunda, coincidiendo con el componente PC-1 calculado para el área de estudio (factor 4 para Cassel, 1986).

Fig. 8. Sucesión del Río Torito 2. Paleobatimetría indicado por la relación P/B, sistema trófico (Van der Zwaan et al., 1999) y asociaciones microfaunales (componentes principales PC-1 y PC-2). Se considera Mioceno Temprano (Aquitaniense), por la última aparición de Lepidocyclina sp. (Loeblich \& Tappan, 1989). 
Ambiente P/B PC-2 PC-1

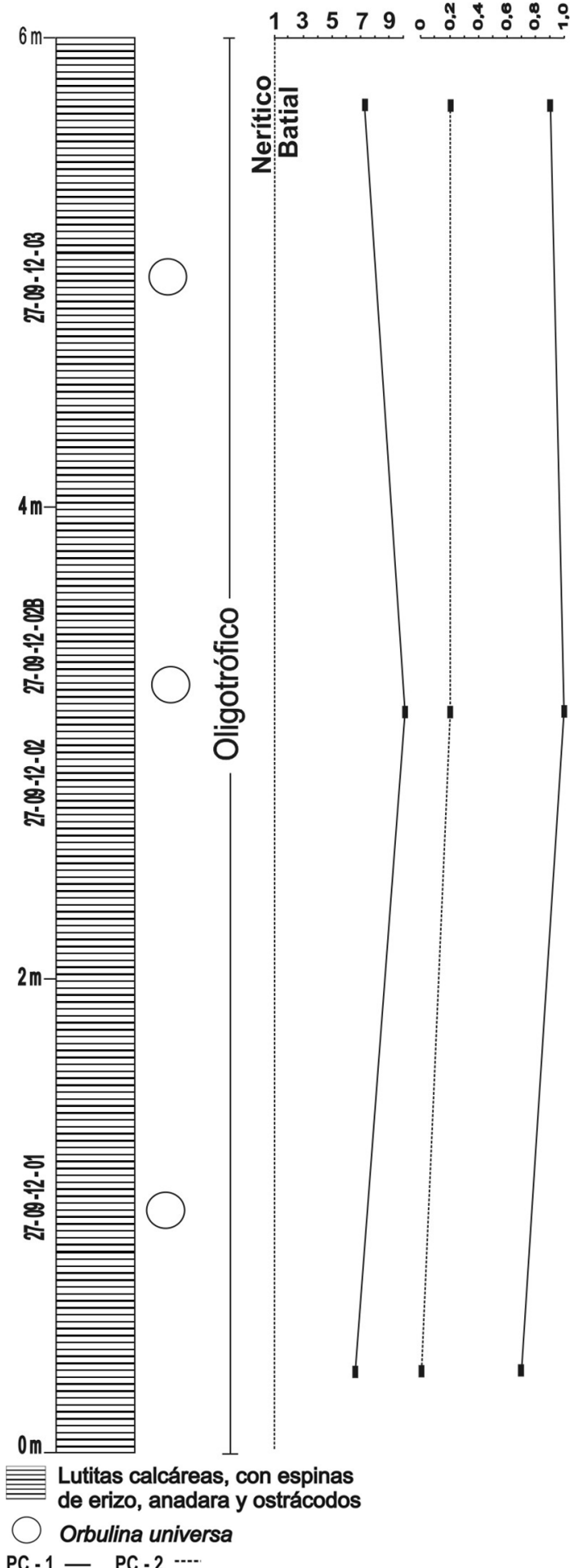

Durante el Mioceno Medio Temprano y el Mioceno Tardío Inferior, la parte media y superior de la sección quebrada Terciopelo, resultó en la transición desde zonas batiales superiores a ambientes de plataforma. La sección tipo del Mioceno Medio Temprano de la quebrada Uscari fue depositada en plataforma continental y está relacionada con la parte superior de la quebrada Terciopelo (Cassel, 1986).

Los cambios de profundidad en el área de estudio, coinciden con lo planteado en el trabajo realizado por Campos (2001), quien describe la sección como superciclo TB2 (Mioceno Temprano - Mioceno Medio). Entre 21-16,5 ma la zona batial cambia a nerítico superior; entre los 16,5-15,5 ma se profundiza hasta nerítico medio (en el área de estudio llega hasta profundidades batiales); para somerizarse nuevamente entre los 15,5-10,5 ma a nerítico superior.

La cuenca de Limón y la de Térraba (lado Pacífico), recibieron aporte del arco volcánico que seguía en continuo desarrollo durante el Mioceno Temprano Tardío a Mioceno Medio Temprano, evidenciado en el área por la montmorillonita encontrada en la zona de río Calvario (Campos, 2001).

Durante parte del Mioceno Temprano y Mioceno Medio, se infiere surgencia oceánica que ha sido confirmada en otras áreas por la presencia de fosforitas en California, Cuba, Jamaica, y Venezuela. Adicionalmente la presencia de glauconita, foraminíferos piritizados y asociaciones específicas de alta productividad (Uvigerina, Globobulimina). En otras áreas la surgencia incluye el Mioceno Tardío y el Plioceno Temprano (Evan \& Michael, 1994).

Los eventos de surgencia en áreas que fueron predominantemente oligotróficas se explican con eventos de circulación oceánica y tectónica. La circulación superficial circumtropical fue interrumpida por el cierre del Tethys oriental entre Arabia actual e Irán. Adicionalmente, se inició

Fig. 9: Sucesión de Guayacán. Paleobatimetría indicado por la relación P/B, sistema trófico (Van der Zwaan et al., 1999) y asociaciones microfaunales (componentes principales PC-1 y PC-2). Se considera de edad Mioceno Medio, por aparición de Orbulina universa (Bolli et al., 1985). 
la circulación profunda circum-Antártica con la apertura del Pasaje de Drake, entre la Antártica y América del sur. Combinando estos eventos se produce un incremento en los giros oceánicos y en la producción de aguas profundas Antárticas. Lo anterior produce un cambio entre la circulación lenta profunda durante el Oligoceno a una circulación profunda, intensa y surgencia durante el Mioceno y de una circulación halotermal (salinidad factor principal) a termohalina (temperatura factor principal) (Roth et al., 2000). La región del Caribe en el Mioceno se caracterizó por aguas frías, turbias, y posiblemente más eutróficas que durante el Oligoceno o el Pleistoceno-Holoceno (Keigwin, 1982; Kennett, 1982; Evan \& Michael, 1994).

La transición a condiciones oligotróficas durante el Mioceno Medio en el Alto Guayacán, puedo deberse a un cambio en la circulación del Componente de Agua Norte (North Component Water, NCW), precursor de la actual Agua Profunda del Atlántico Norte (North Atlantic Deep Water, $N A D W$ ), caracterizada por aguas oxigenadas, ricas en carbonatos y pobre en nutrientes (Roth et al., 2000).

La región adicionalmente a los cambios oceanográficos, también sufrió cambios climáticos globales. Con isótopos de oxígeno y termometría (Mg-Ca) se determina un enfriamiento progresivo de $12^{\circ} \mathrm{C}$ durante los intervalos, Eoceno Temprano a Medio, límite Eoceno-Oligoceno (33,5-34ma) y Mioceno Medio Tardío (14 ma - MMTO -Mid Miocene Termal Optimum); asociados con el crecimiento de la Antártica debido a una caída del CO2 (Cronin, 2010). Entre estos intervalos fríos ocurren eventos de calentamiento global durante el Paleoceno-Eoceno (55 ma) y entre 18-14 ma. Este último evento podría coincidir con el intervalo de profundización ocurrido en el área de estudio.

\section{AGRADECIMIENTOS}

Se agradece a la Vicerrectoría de Investigación por el apoyo al proyecto $\mathrm{N}^{\circ} 113-\mathrm{B} 1-240$ "Foraminíferos bentónicos como indicadores paleoecológicos de la Formación Uscari”. Al M.Sc. Rolando Mora Chinchilla por el apoyo per- manente a este proyecto; a los geólogos Sergio Hernández y Benjamín Acevedo por la lectura crítica de este artículo. Jose Daniel López por la elaboración de la figura 1, a los asistentes del laboratorio de Paleontología y las valiosas correcciones realizadas por el revisor de este artículo.

\section{REFERENCIAS BIBLIOGRAFICAS}

BARAHONA, D., MENDEZ. J., \& SJOBOHM, L., 2013: Análisis de la susceptibilidad a deslizamientos en el distrito de Tres Equis: una base para la gestión del riesgo y ordenamiento territorial, Turrialba, Costa Rica.- 120 págs. Univ. de Costa Rica, San José [Tesis Lic.].

BERGEN, F.W., \& O’NEIL, P., 1979: Distribution of Holocene Foraminifera in the Gulf of Alaska.- J. Paleont. 53(6): 1267-1292.

BOLLI, H., SAUNDERS. J. \& PERCH-NIELSEN, K., 1985: Plankton Stratigraphy.- 1040 págs. Cambrige University Press, New York.

BOLLI, H., BECKMANN, J-P, \& SAUNDERS, J., 1964: Benthic Foraminiferal Biostratigraphy of the South Caribbean Region.- 408 págs. Cambrige University Press, New York.

BRANDES, C., ASTORGA, A., BACK, S., LITTKE, R. \& WINSEMANN, J., 2007: Deformation Style and Basin - Fill Architecture of the Offshore Limón Back - Arc Basin (Costa Rica).- Marine and Petroleum Geol. 24: 277-287.

BRASIER, M.D., 1980: Microfossils.- 193 págs. George Allen \& UNWIN, Londres.

BROWNE, H., 1961: Paleontological and Stratigraphic Report of Limon Province, Costa Rica and Northeastern Panamá.Informe GRCR-59. 
CASSELL, D., 1986: Neogene Foraminifera of the Limon Basin of Costa Rica.- 323 págs. Louisiana State Univ., Louisiana [Tesis Ph.D.].

CASSEL, D.T. \& SEN GUPTA, B.K., 1989: Pliocene Foraminifera and Environments, Limon Basin of Costa Rica.- J. Paleont. 63(2): 146-157.

CAMPOS, L., 2001: Geology and Basin History of Middle Costa Rica; an Interoceanic Island Arc in the Convergence Between the Caribbean and the Central Pacific Plates.Tubinger Geowiss. Arb., Reihe A62: 1138.

CHAVARRÍA, F., 1996: Estudio Geológico Geotécnico del Corredor Turrialba Siquirres-Sección Río Torito - Laguna Bonilla. Poliducto de Recope. Provincia de Cartago, Costa Rica.- 79 págs. Univ. de Costa Rica, San José [Inf. Campaña Geol.].

COLLINS, L.S., \& COATES, A.G., 1999: A Paleobiotic Survey of Caribbean Faunas from the Caribbean Coast of the Isthmus of Panama.- Bull. Amer. Paleont. 357: 351.

CORLISS, B.H. \& CHEN, C., 1988: Morphotype Patterns of Norwegian Sea Deep - Sea Benthic Foraminifera and Ecological Implications.- Geology, 16: 716-719.

CRONIN, T., 2010: Paleoclimates.- 441 págs. Columbia University Press, New York.

DOUGLAS, R.G., 1979: Benthic Foraminiferal Ecology and Paleoecology.- Soc. Economic Paleontologists and Mineralogists (SEPM), Short Course, 6: 21-53.

EVAN, N.E. \& MICHAEL J.R., 1994: OligoceneMiocene Extinction and Geographic Restriction of Caribbean Corals: Roles of Turbidity, Temperature, and Nutrients.PALAIOS, 9: 576-598.
GOODAY, A.J., 1994: The Biology of Deep Sea Foraminifera: A Review of Some Advances and Their Applications in Paleoceanography.- PALAIOS, 9: 14-31.

INGLE, J.C., KELLER, G. \& KOLPACK, R.L., 1980: Benthic Foraminiferal Biofacies, Sediments and Water Masses of the Souther Perú-Chile Trench Area, Southeastern Pacific Ocean.- Micropaleont. 26(2): 113150.

HAMMER, O., HARPER, D.A.T. \& RYAN, P.D., 2001: PAST, Paleontological Statistic Software Package for Education and Data Analysis. Palaeont. Electronica 4(1): http:// folk.uio.no/ohammer/past/. [Consulta: 01 de junio de 2013].

KAMINSKI, M., SILYE, L., \& KENDER, S., 2005: Miocene Deep-Water Agglutinated Foraminifera from ODP Hole 909c: Implications for the Paleoceanography of the Fram Strait Area, Greenland Sea.Micropaleont. 51(5): 373-403.

KEIGWIN, L., 1982: Isotopic Paleoceanography of the Caribbean and East Pacific: Role of Panama Uplift in Late Neogene Time.Science, 217: 350-352.

KENNETT, J.P., 1982: Marine Geology.- 813 págs. Prentice Hall, New Jersey.

LAURITO, C.A., 1996: El Género Isistius (Squalidae) en el Alto de Guayacán. Formación Uscari (Mioceno SuperiorPlioceno Inferior), Provincia de Limón, Costa Rica.- Rev. Geol. Amér. Central, 19/20: 87- 92.

LAURITO, C.A., 1996: Análisis preliminar de la ictiofauna de Alto Guayacán (Costa Rica) con base en los otolitos. Formación Uscari (Mioceno Superior-Plioceno Inferior).- Rev. Geol. Amér. Central, 19/20: 93- 109. 
LAURITO, C.A., 1999: Los cetáceos fósiles de la localidad de Alto Guayacán (y otros ictiolitos asociados). Mioceno Superior/ Plioceno Inferior de la Formación Uscari, provincia de Limón, CR.- 124 págs. Texto Comunicación S.A., San José.

LOEBLICH, A.R. \& TAPPAN, H., 1964: Sarcodina and Foraminifera.- En: MOORE, R.C. (ed.): Treatise on Invertebrate Paleontology, Part C, Protista, 2.- 900 págs. Kansas University \& Geological Society of America, Lawrence.

LOEBLICH,A.R. \&TAPPAN,H., 1988: Foraminiferal Genera and their Classification.- 869 págs. Department of Earth and Space Science \& University of California, Los Angeles.

LOUBERE, P., 1996: The Surface Ocean Productivity and Bottom Water Oxygen Signals in Deep Water Benthic Foraminiferal Assemblages.- Marine Micropaleont. 28: 247-261.

McALEECE, N., GAGE, J.D.G., LAMBSHEAD, P.J.D. \& PATERSON, G.L.J., 1997: BioDiversity Professional Statistic Analysis Software. http://www.sams. ac.uk/peter-lamont/biodiversitypro\#sthash.7kmalish.dpuf. [Consulta: 01 de junio de 2013].

McCORKLE, D.C. \& EMERSON, S.R., 1988: The Relationship Between Pore Water Carbon Isotopic Composition and Bottom Water Oxygen Concentration.- Geochimical et Cosmochimica Acta, 52: 1169-1178.

MULLINS, H.T., THOMPSON, J.B., Mc DOUGALL, K., \& VERCOUTERE, T.L., 1985: Oxygen-Minimum Zone Edge Effects: Evidence from Central California Coastal Upwelling System.- Geology, 13: 491-494.
MURRAY, J.W., 2006: Ecology and Applications of Benthic Foraminifera.- 426 págs. Cambridge University Press, New York.

NAGY， J. \& SEIDENKRANTZ, M. 2003: New Foraminiferal Taxa and Revised Biostratigraphy of Jurassic Marginal Marine Deposits on Anholt, Denmark.Micropaleont. 49(1): 27-46.

PEREZ, W., 1996: Estudio geológico y amenazas naturales corredor Turrialba-Siquirres, poliducto Recope, sector Lagunilla, BonillaGuayacán.- 71 págs. Univ. de Costa Rica, San José [Inf. Campaña Geol.].

PIZARRO, D., 1985: Bioestratigrafía de la Formación Uscari en base a foraminíferos planctónicos/ Mioceno Medio a Superior, Costa Rica.- 34 págs. Univ. de Costa Rica, San José [Tesis Lic.].

RAMÍREZ, A., 1999: Ecología aplicada. diseño y análisis estadístico.- 325 págs. Fundación Univ. Jorge Tadeo Lozano, Bogotá.

ROTH, J., DROXLER, A. \& KAMEO, K., 2000: The Caribbean Carbonate Crash at the Middle to Late Miocene Transition: Linkage to the Establishment of the Modern Global Ocean Conveyor.- Proceedings of the Ocean Drilling Program, Scientific Results, 165: 249-273.

SIBAJA, G., 1996: Estudio geológico - geotécnico del Corredor Turrialba - Siquírres. poliducto Recope. Sección Turrialba - Río Torito.- 88 págs. Univ. de Costa Rica, San José [Inf. Campaña Geol.].

VAN DER ZWAAN, G.J., DUIJNSTEE, I.A.P., DULK, M., ERNST, S.R., JANNINK, N.T. \& KOUWENHOVEN, T.J., 1999: Benthic Foraminifers: Proxies or Problems? A Review of Paleoecological Concepts.Earth Sci. Rev. 16: 213-236. 